\title{
Effect of Fire Induced Spalling on the Response of Reinforced Concrete Beams
}

\author{
Kodur V.K.R. ${ }^{1)}$ and Dwaikat M.B. ${ }^{2)}$
}

(Received May 29, 2008, Revised September 30, 2008, Accepted October 31)

\begin{abstract}
A macroscopic finite element model is applied to investigate the effect of fire induced spalling on the response of reinforced concrete (RC) beams. Spalling is accounted for in the model through pore pressure calculations in concrete. The principles of mechanics and thermodynamics are applied to compute the temperature induced pore pressure in the concrete structures as a function of fire exposure time. The computed pore pressure is checked against the temperature dependent tensile strength of concrete to determine the extent of spalling. Using the model, case studies are conducted to investigate the influence of concrete permeability, fire scenario and axial restraint on the fire induced spalling and also on the response of RC beams. Results from the analysis indicate that the fire induced spalling, fire scenario, and axial restraint have significant influence on the fire response of $\mathrm{RC}$ beams. It is also shown that concrete permeability has substantial effect on the fire induced spalling and thus on the fire response of concrete beams. The fire resistance of high strength concrete beams can be lower that that of normal strength concrete beams due to fire induced spalling resulting from low permeability in high strength concrete.
\end{abstract}

Keywords: fire induced spalling, pore pressure, numerical model, fire resistance, concrete beams.

\section{Introduction}

Reinforced concrete (RC) structural systems are quite frequently used in high rise buildings and other built infrastructure due to a number of advantages they provide over other materials. When used in buildings, the provision of appropriate fire safety measures for structural members is an important aspect of design since fire represents one of the most severe environmental conditions to which structures may be subjected in their life time. The basis for this requirement can be attributed to the fact that, when other measures for containing the fire fail, structural integrity is the last line of defense.

In recent years, high strength concrete (HSC) is being widely used in place of normal strength concrete (NSC). This is due to significant economic, architectural, and structural advantages HSC can provide as compared to conventional NSC. With the increased use of HSC, concern has developed regarding the behavior of such concretes under fire scenarios. The occurrence of fire induced spalling is one of the major reasons for this concern.

Generally, concrete structural members (mainly comprising of NSC) exhibit good performance under fire situations. However, HSC may not exhibit the same level of performance (as that of NSC) under severe fire conditions. This is mainly due to faster

\footnotetext{
${ }^{1)} \mathrm{CEE}$ Dept., Michigan State University, MI 48824, USA. E-mail: kodur@egr.msu.edu

${ }^{2)}$ CEE Dept., Michigan State University, MI 48824, USA. Email: dwaikatm@msu.edu

Copyright (c) 2008, Korea Concrete Institute. All rights reserved, including the making of copies without the written permission of the copyright proprietors.
}

degradation of properties at high temperatures and occurrence of fire induced spalling. While spalling can occur in all concrete types when exposed to rapid heating (such as the one encountered in fires), results from a number of studies ${ }^{1-6}$ have shown that HSC is more susceptible to fire induced spalling than NSC. The high compactness and low permeability of HSC (often due to the presence of silica fume) accelerate the pore pressure development leading to spalling, that can be explosive under some conditions. Such spalling has the effect of reducing the cross sectional area of the structural member, and increasing the heat penetration to the steel reinforcement. Thus, spalling might lead to reduction in strength and stiffness of RC structural members, which in turn might cause early failure of RC members under fire conditions ${ }^{7}$.

Fire induced spalling in concrete structures have been observed both in laboratory experiments and under real fire conditions. ${ }^{3,8}$ At present, there is very limited information on the ways to incorporate spalling in fire resistance calculations. This is mainly due to lack of reliable high temperature material properties and calculations methodologies for predicting spalling in concrete.

In this paper, a macroscopic finite element model, which accounts for fire induced spalling in concrete is applied to study the influence of spalling on the fire performance of RC beams. Using the model, case studies are carried out to investigate the effect of critical parameters, namely; concrete permeability and thus spalling, heating regime and axial restraint on the response of RC beams.

\section{Fire induced spalling in concrete}

A review of literature presents a conflicting picture on the 
occurrence of spalling and also on the exact mechanism for spalling. ${ }^{2,7,9}$ While many research studies illustrated explosive spalling in concrete members under laboratory conditions, there are a few other studies which report little or no significant spalling. One possible explanation for this confusing trend of observations is the large number of factors that influence the spalling and the interdependency of some of these factors.

However, most researchers agree that the major causes for spalling are low permeability of concrete and moisture migration which results in the build-up of pore pressure at elevated temperatures. ${ }^{2,710} \mathrm{HSC}$ is believed to be more susceptible to this pressure build-up because of its low permeability compared to NSC. The extremely high water vapor pressure, generated during exposure to fire, cannot escape due to the high density of HSC and this pressure can reach the saturation vapor pressure. At $300^{\circ} \mathrm{C}$, the pore pressure often reaches about $8 \mathrm{MPa}$. Such internal pressures are too high to be resisted by the HSC having a tensile strength of about $5 \mathrm{MPa}^{2}$

Permeability of concrete depends on many factors including porosity, poor size distribution, connectivity of the pores, and tortuosity of the concrete pores. Thus, concretes with similar level of porosity, can have different degrees of permeability due to variations in other factors. Typically, NSC with compressive strengths varying from 20 to $70 \mathrm{MPa}$, can have permeability in the range of $10^{-13}$ to $10^{-16} \mathrm{~m}^{2}$ while $\mathrm{HSC}$ with strength above $70 \mathrm{MPa}$ can have permeability in the range of $10^{-16}$ to $10^{-20} \mathrm{~m}^{2}$. Fire induced spalling is largely influenced by concrete permeability, fire severity and also factors such as moisture content. However, it should be noted that spalling may not occur even in higher strengths of concrete provided that the permeability is high. This explains the reason for spalling not to occur all the time in HSC members during fire tests.

A detailed literature review indicates that there have been limited analytical and experimental studies to investigate the effect of spalling on the fire response of RC members. ${ }^{11}$ These studies focused mostly on RC columns under standard fire scenarios, without any consideration for cooling phase of the fire exposure. Further, there have been no studies to investigate the influence of spalling on the fire response of HSC beams under design fire scenarios.

The literature review also shows that there is very limited guidance in current codes and standards for predicting fire induced spalling in concrete. However, some codes and standards include broad guidelines for estimating spalling and for mitigating spalling. Eurocode Specifications ${ }^{12}$ state that spalling is unlikely to occur when the moisture content of concrete is lower than $3 \%$, without any due consideration to permeability and the tensile strength of concrete. ACI 216.1 standard $^{13}$ does not have any specifications for predicting spalling in concrete. However, this standard provides some guidelines for mitigating spalling through the addition of polypropylene fibers to concrete mix. It should be noted that the guidelines on fire induced spalling in current codes are mainly derived based on observation during fire tests on small specimens and do not give consideration to critical factors that influence spalling in concrete. One of the main reasons for slow progress in developing rational methods for predicting spalling, and also for developing solutions to mitigate spalling, is the lack of calculation methodologies for predicting spalling.

\section{Numerical model}

\subsection{General}

A macroscopic finite element model, developed by Dwaikat and Kodur, ${ }^{13}$ is used to carry out the fire resistance analysis of RC beams. For the analysis, the RC beam is divided into a number of segments along its length and the mid-section of the segment is assumed to represent the behavior of the whole segment. The cross section, representing each segment, is subdivided into elements forming a two dimensional mesh. The fire resistance analysis is carried out by incrementing time in steps. At each time interval, the analysis is performed through three main steps:

- Establishing fire temperature due to fire exposure,

- Carrying out coupled heat transfer-spalling analysis in each segment to predict cross sectional temperature and spalling, and

- Performing strength and deflection analysis, which is carried out, through three substeps:

- Calculating the axial restraint force in the RC beam,

- Generation of M-k relationships (utilizing the axial restraint force computed above) for each beam segment, and

- Performing structural analysis of the beam to compute deflections and internal forces.

The fire temperature is established using standard or design fire scenarios. Once the fire temperature is established, the next step is thermal analysis to evaluate cross sectional temperatures in each segment of the beam. In the previous version of the model, spalling is accounted for using a simplified approach. ${ }^{13}$ However, this has been extended by including a new spalling sub-model which involves pore pressure calculations. Further details on the spalling sub-model are provided in the following section.

\subsection{Spalling sub-model}

A spalling sub-model has been incorporated into the macroscopic finite element model for predicting fire induced spalling. In this sub-model, spalling is evaluated at each time step through pore pressure calculations in concrete when it is subjected to fire. This hydrothermal model uses the principles of mechanics and thermodynamics including the conservation of mass of liquid water and water vapor to predict the pore pressure in the concrete. The following assumptions are made in the development of spalling sub-model ${ }^{11}$ :

- Concrete is a continuum medium. This assumption is based on the fact that the heterogeneity scale (length over which the medium changes from one phase to another) of concrete is much smaller than the length over which a change can be observed in the temperature, moisture content, and pressure.

- Water vapor is an ideal gas, which is valid for most engineering applications.

- Mobility of liquid water is ignored. This assumption is valid because Darcy's coefficient (permeability) for liquid water in concrete is much smaller than that for water vapor.

- The effect of air is ignored in the analysis. This assumption is considered to be valid because the mass of air in concrete is much smaller than the mass of water.

- The solid skeleton is assumed to be undeformable. This is because the mechanical and thermal deformation of the solid phase is small when compared to the volume changes due to 
other processes such as evaporation.

- Water is incompressible liquid. This assumption is valid because the volumetric deformation of liquid water due to pressure is much smaller than the volumetric changes due to other processes such as evaporation.

- The applied loading is assumed not to influence the hydrothermal analysis. The applied loading generally causes damage in concrete which increases the concrete permeability. Thus, by ignoring such effect conservative spalling predictions can be obtained.

- The effect of latent heat and heat of dehydration is not accounted for in the analysis. Accounting for latent heat and heat of dehydration will slightly reduce the predicted temperatures. Thus, latent heat and heat of dehydration can be conservatively ignored in the analysis.

The governing equations for the calculation of vapor pressure in concrete are derived using four main principles, namely:

- Conservation of mass for liquid water,

- Ideal gas law,

- The total volume of all different components in a unit volume of concrete equals unity, and

- Conservation of mass for water vapor.

In the hydrothermal model, and using the conservation of mass for water vapor, the mass transfer equation for water vapor inside heated concrete, at a given time step, can be written as:

$$
A \frac{d P_{V}}{d t}=\nabla B \nabla P_{V}+C
$$

where, $P_{V}=$ pore pressure, $t=$ time, $A, B$ and $C=$ parameters that depend on pore pressure, temperature, rate of increase in temperature, permeability of concrete, initial moisture content, and the isotherm used in the analysis. Isotherms are used to predict the liquid water inside concrete as a function of pore pressure for a constant temperature. The variables, $A, B$ and $C$ are derived using the first three principles (outlined above), as well as the constitutive laws of concrete and are given by the following equations:

$A=\left[\left(1-\frac{m_{V}}{V_{V} \rho_{L}}\right) \frac{d m_{L}}{d P_{V}}+\frac{V_{V} M}{R T}\right]$

$$
B=m_{V} \frac{k_{T}}{\mu_{V}}
$$

$C=\left[\left(1-\frac{m_{V}}{V_{V} \rho_{L}}\right)\left(-\frac{d m_{L}}{d T}+\frac{d m_{D}}{d T}\right)+\frac{m_{V}}{T}+\frac{m_{V}}{V_{V} \rho_{L}^{2}} \frac{d \rho_{L}}{d T}\left(m_{D}-m_{L}\right)\right] \frac{d T}{d t}$

where, $m_{V}=$ mass of water vapor, $R=$ gas constant, $M=$ molar mass of water, $V_{V}=$ volume fraction of water vapor, $P_{V}=$ vapor pressure, $T=$ temperature, $m_{D}=$ mass of liquid water formed due to dehydration, $\rho_{L}=$ density of liquid water, $k_{T}=$ Intrinsic permeability of concrete at temperature, $T, \mu_{V}=$ dynamic viscosity of water vapor, and $m_{L}=$ mass of liquid water at any time, $t$, which can be determined from the isotherms used in the analysis. More details on the pore pressure computation including the derivation of equations are given in Reference 11.

Finite element analysis is used to solve Eq. (1) and compute the pore pressure distribution within the midsection of each segment along the length of the beam. The resulting pore pressure is compared with the temperature dependent tensile strength of concrete as shown in Fig. 1. Spalling is said to occur when the pore pressure exceeds the tensile strength of concrete; i.e., when the following expression is satisfied:

$$
n P_{V}>f_{t T}
$$

where, $n=$ porosity of concrete, $f_{t T}=$ tensile strength of concrete for temperature, $T$. Once spalling of concrete occurs, the reduced concrete section and the new boundary surface are considered in the thermal and strength analyses in subsequent time steps. In this way, the spalling and thermal calculations are coupled in the analysis. The validity of the spalling sub-model is established by comparing the temperature, pore pressure and concrete spalling predictions with results from fire tests. More details on the model validation can be found in References 11 and 14 .

\subsection{Strength analysis}

The resulting temperature and spalling perditions, at each time step, are used as an input for undertaking strength analysis. The model uses segmental moment curvature relationships to trace the response of an $\mathrm{RC}$ beam in the entire range of loading up to collapse under fire. The axial restraint force is computed through an iterative procedure that satisfies compatibility, equilibrium and convergence criteria along the span of the beam. The effect of fire induced axial restraint force is accounted for in the generation of the moment curvature relationships. In the model, the boundaries restraining the beam are idealized as a spring of stiffness $(k)$ as shown in Fig. 2. The value of $k$ can be changed to account for varying degrees of restraint. The second order effects are considered in the model by incorporating the developed secondary moments and forces to the applied loading.

The model is capable of undertaking fire resistance analysis for beams exposed to any given fire time temperature curve. Various strain components including mechanical strain, thermal strain, and creep strain for both concrete and reinforcing steel and the transient strain in concrete are accounted for in the model based on the relationships proposed by Harmathy, ${ }^{15,16}$ and Anderberg and Thelandersson, ${ }^{17}$ respectively. The high temperature creep and transient strains, which are not often accounted for, might play a significant role fire behavior of $\mathrm{RC}$ beams, particularly deflections

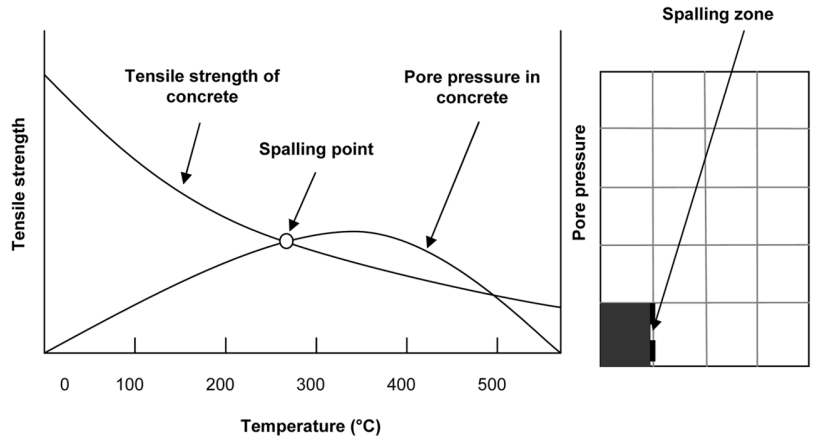

Fig. 1 Illustration of spalling prediction in the proposed model. 


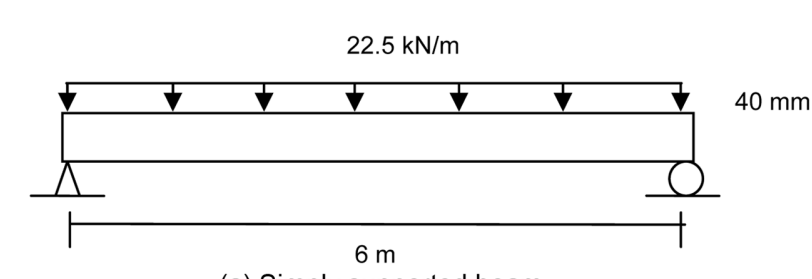

(a) Simply supported beam

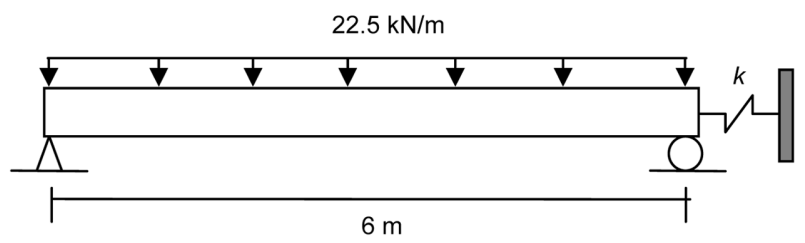

(b) Axially restrained beam

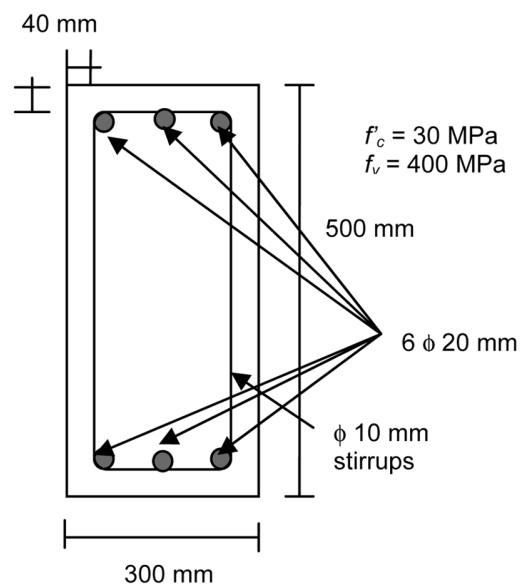

(c) Cross section

Fig. 2 Cross section and elevation of RC beam used in parametric studies.

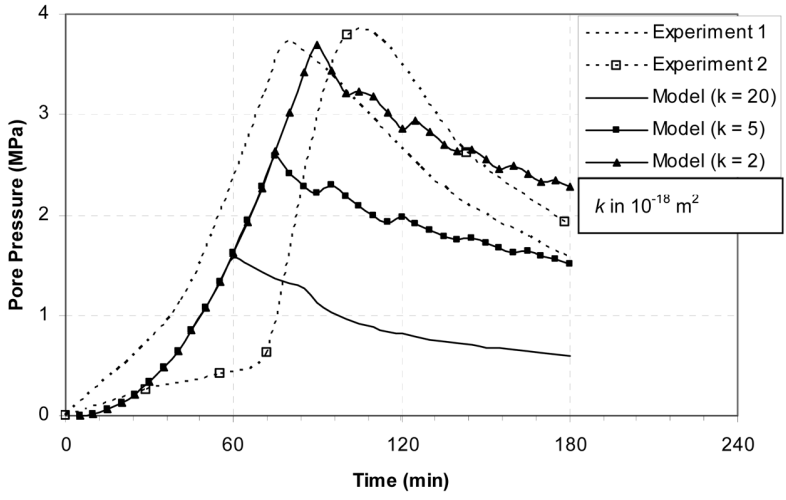

Fig. 3 Measured and predicted pore pressure at depth of $20 \mathrm{~mm}$ from exposed surface.

in the later stages of fire exposure.

The computer model generates various critical output parameters, such as temperatures, stresses, strains, deflections, fire induced axial restraint force and moment capacities at various fire exposure times. The output parameters can be used to check against predetermined four sets of failure criteria, which include prescriptive thermal limit state, strength and deflection considerations. The numerical model was validated against test results from full-scale fire tests conducted on RC beams and reported in the literature. Full details of the numerical procedure, including the derivation of appropriate equations, are presented by Dwaikat and Kodur. ${ }^{14}$

\section{Model validation}

Full details on the validity of the previous version of the model (where the hydrothermal spalling sub-model was not included) were presented elsewhere. ${ }^{14}$ Due to the lack of test data on HSC beams exposed to fire, the validity of the spalling sub-model is established by comparing predictions from the model with those from fire tests on concrete slabs and blocks. The pore pressure predictions from the model are compared with measured values in tests conducted by Kalifa et al. ${ }^{18}$. They tested $120 \mathrm{~mm}$ thick RC slabs by exposing them to elevated temperature through rapid heating from one side. A heating rate of $5^{\circ} \mathrm{C} /$ second $\left(300^{\circ} \mathrm{C} /\right.$ minute) was used for the first two minutes and then the temperature is kept at $600^{\circ} \mathrm{C}$. The heating rate used in the test is compara- ble to the heating rate in standard fire scenarios such as ASTM E119. ${ }^{19}$ The pore pressure was measured at three different locations, namely; $20 \mathrm{~mm}, 30 \mathrm{~mm}$, and $40 \mathrm{~mm}$, from the heated side. The analysis was carried out by using the material properties reported in the experimental studies. Results from the numerical model are compared with test data in Figs. 3 5.

The pore pressure predictions were carried out for three values of initial permeability, namely; $20 \times 10^{-18} \mathrm{~m}^{2}, 5 \times 10^{-18} \mathrm{~m}^{2}$, and $2 \times 10^{-18} \mathrm{~m}^{2}$, as can be seen in Figs. 3-5. It can be seen from the figures that the pore pressure increases with fire exposure time until it reaches a maximum value, and then it decreases. The attainment of peak in pore pressure can be attributed to moisture clog that results from moisture migration in concrete. Part of the water in the concrete, close to the exposed surface, evaporates resulting in a significant increase in the pore pressure. The build up of pore pressure forces part of water vapor to migrate to the heated surface. Another part of water vapor migrates deep inside concrete where the vapor condensates and results in saturation of concrete. The above phenomenon is referred to as moisture clog and this effect can produce significant variation in pore pressure in concrete. The figures also show that reducing the concrete permeability will increase the developed pore pressure at any fire exposure time. As an illustration, for the three locations where the pore pressure was measured, a peak pore pressure of about $2 \mathrm{MPa}$ is predicted for concrete permeability of $20 \times 10^{-18} \mathrm{~m}^{2}$. However, for

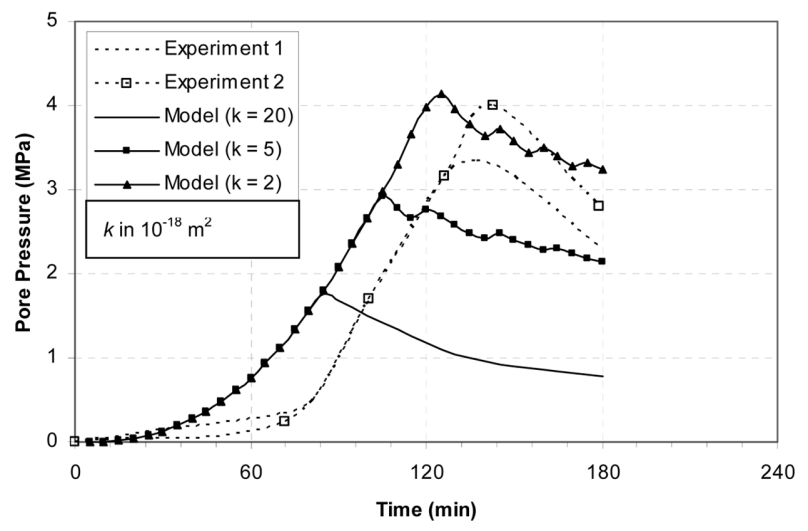

Fig. 4 Measured and predicted pore pressure at depth of $30 \mathrm{~mm}$ from exposed surface. 
a permeability of $2 \times 10^{-18} \mathrm{~m}^{2}$ a peak pore pressure of about 4 $\mathrm{MPa}$ is predicted. It can also be seen, from Figs. $3 \sim 5$, that the results from the model compare well with the experimental results for permeability of $2 \times 10^{-18} \mathrm{~m}^{2}$. This value of permeability is between the residual permeability reported by Kalifa et al. ${ }^{18}$ for the same concrete heated to $80^{\circ} \mathrm{C}\left(4 \times 10^{-18} \mathrm{~m}^{2}\right)$ and the maximum permeability of concrete at room temperature given by Baroghel-Bouny et al. ${ }^{20}\left(5 \times 10^{-22} \mathrm{~m}^{2}\right)$. However, Fig. 5 shows that the pore pressure predicted by the model is higher than the measured values for most of the fire exposure time. This can be attributed to the variation of the permeability of concrete with temperature and pore pressure which is not fully understood. Overall, the spalling model seems to overestimate the pore pressure in concrete and thus leads to conservative estimates for spalling predictions.

The validation of the model is also established by comparing the spalling predictions with the measured spalling values in the fire tests conducted by Bilodeau et al. ${ }^{5}$. In their tests, concrete blocks of $610 \times 425 \times 770 \mathrm{~mm}$ size were exposed to ASTM E1529 $9^{21}$ hydrocarbon fire from one side. Six blocks, with different test variables, were tested by exposing them to fire in a furnace for 2 hours. Of the six blocks tested under fire, Block no. 5, which was made without polypropylene fibers, had the largest amount of spalling, and thus this block is used for the validation of the model. The measured and predicted reduction in the block thickness as a function of fire exposure time is presented in Fig. 6. It should be noted that spalling was only measured at the end of the fire test and not throughout the test. Thus, the reduced block thickness was

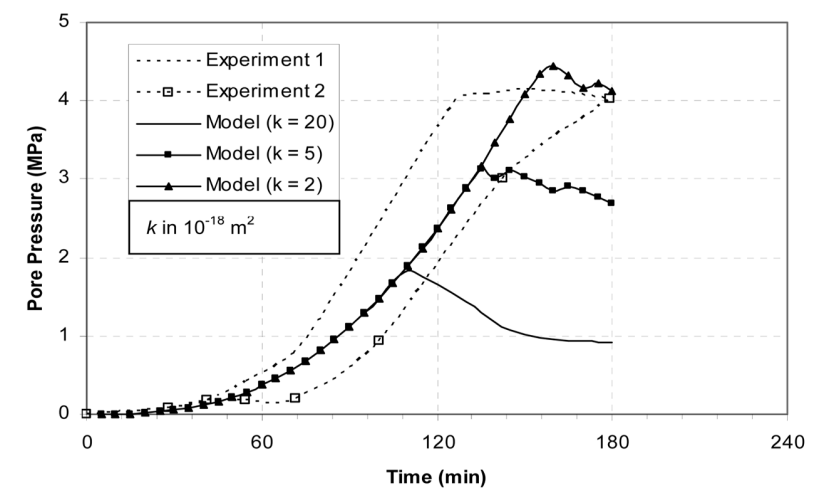

Fig. 5 Measured and predicted pore pressure at depth of $40 \mathrm{~mm}$ from exposed surface.

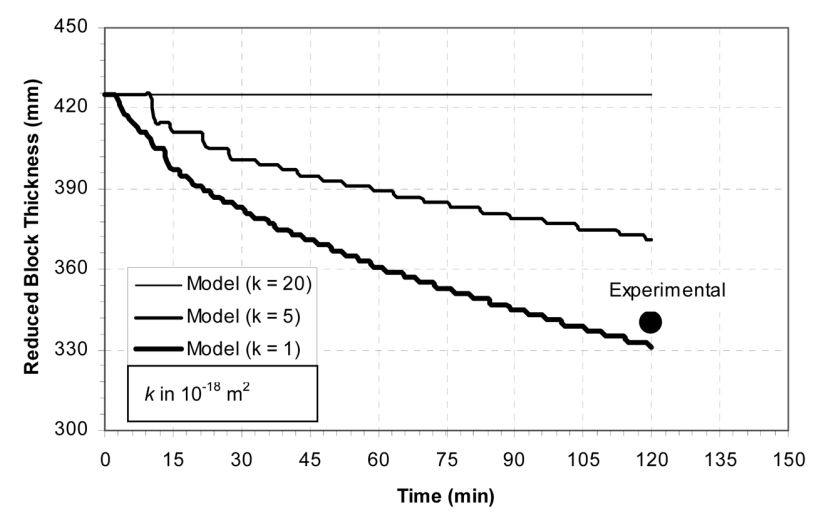

Fig. 6 Measured and predicted block thickness as a function of time. only measured at the end of the test as can be seen in Fig. 6. Since the exact concrete permeability was not reported in the tests, the analysis was carried out by assuming three values of permeability, namely; $20 \times 10^{-18} \mathrm{~m}^{2}, 5 \times 10^{-18} \mathrm{~m},{ }^{2}$ and $1 \times 10^{-18} \mathrm{~m}$, The comparisons in Fig. 6 show that, when concrete permeability of $1 \times 10^{-18} \mathrm{~m}^{2}$ is used, a good prediction of concrete spalling is obtained. The figure also shows that the permeability of concrete has significant influence on fire induced spalling with no spalling predicted for concrete with permeability higher than $20 \times 10^{-18} \mathrm{~m}^{2}$

\section{Case studies}

The main objective of the case studies is to investigate the effect of three parameters, namely; permeability (spalling), fire scenario and axial restraint on the fire resistance of RC beams using the extended model described above. Also, the results from the extended model are compared with those from the previous model through comparing the effect of these parameters on the fire response of HSC and NSC beams. Details of the analyzed beams and the analysis results are give in the following sections.

\subsection{Analysis variables}

Two sets of RC beams (each set comprising of four RC beams) were analyzed to investigate the influence of fire induced spalling on the fire response of $\mathrm{RC}$ beams. One beam in each set is made of NSC while the remaining three are made of HSC. The beams in the first set are simply supported (SS), while the beams in the second set are axially restrained (AR). The axial restraint stiffness $(k)$ is assumed to be $50 \mathrm{kN} / \mathrm{mm}$ for the axially restrained beams. This value of the axial restraint stiffness is selected in such a way that it represents restraint conditions encountered in practice. ${ }^{14}$ Each beam is analyzed under four fire scenarios including standard and design fire exposures. The analysis was carried out using the macroscopic finite element model in five minute time increments till failure occurred in the beam. Failure is said to occur when the strength limit state is exceeded in any segment of the beam. While the model is capable of applying either thermal, strength or deflection failure limit state, for the sake of simplicity, only strength limit state is considered here. Full details on the effect of different failure criteria on the fire resistance of RC beams are presented elsewhere. ${ }^{22}$ Results from the analysis are summarized in Table 1.

\subsection{Beam details}

All the analyzed RC beams are of rectangular cross section $(300 \mathrm{~mm}$ $\times 500 \mathrm{~mm}$ ) and have a span length of $6 \mathrm{~m}$ as shown in Fig. 2. The compressive strength and permeability for the NSC are assumed to be $30 \mathrm{MPa}$, and $10^{-16} \mathrm{~m}$, respectively. For HSC, the compressive strength is assumed to be $100 \mathrm{MPa}$, and three values of permeability, namely; $10^{-18} \mathrm{~m}^{2} 10^{-19} \mathrm{~m},{ }^{2}$ and $10^{-20} \mathrm{~m}^{2}$ are assumed. The beams were reinforced with steel rebars having yield strength of $400 \mathrm{MPa}$. The room temperature capacity of the analyzed beams was calculated based on ACI 318 provisions. ${ }^{23}$ The applied loading on the beam shown in Fig. 2, is calculated for a dead load to live load ratio of 2, based on ASCE $07^{24}$ (1.2 dead load + 1.6 live load for room temperature calculation, and 1.2 dead load +0.5 live load under fire conditions). For load calculations, the ultimate load at room temperature is equated to the room temperature capacity of each beam. The difference in the computed load for 
Table 1 Summary of the fire resistance values for the analyzed beams.

\begin{tabular}{|c|c|c|c|c|c|}
\hline Case & Beam designation & Concrete Type & Permeability (m2) & Type of fire exposure & Fire resistance (minutes) \\
\hline \multirow{16}{*}{ SS beam } & BNS11 & \multirow{4}{*}{ NSC } & \multirow{4}{*}{$10^{-16}$} & ASTM E119 & 145 \\
\hline & BNS12 & & & Hydrocarbon & 120 \\
\hline & BNS13 & & & Design Fire I & $\mathrm{NF}^{*}$ \\
\hline & BNS14 & & & Design Fire II & $\mathrm{NF}$ \\
\hline & BHS11 & \multirow{12}{*}{ HSC } & \multirow{4}{*}{$10^{-18}$} & ASTM E119 & 60 \\
\hline & BHS12 & & & Hydrocarbon & 40 \\
\hline & BHS13 & & & Design Fire I & 35 \\
\hline & BHS14 & & & Design Fire II & $\mathrm{NF}$ \\
\hline & BHS21 & & \multirow{4}{*}{$10^{-19}$} & ASTM E119 & 55 \\
\hline & BHS22 & & & Hydrocarbon & 35 \\
\hline & BHS23 & & & Design Fire I & 30 \\
\hline & BHS24 & & & Design Fire II & $\mathrm{NF}$ \\
\hline & BHS31 & & \multirow{4}{*}{$10^{-20}$} & ASTM E119 & 55 \\
\hline & BHS32 & & & Hydrocarbon & 35 \\
\hline & BHS33 & & & Design Fire I & 30 \\
\hline & BHS34 & & & Design Fire II & $\mathrm{NF}$ \\
\hline \multirow{16}{*}{ AR beam } & BNA11 & \multirow{4}{*}{ NSC } & \multirow{4}{*}{$10^{-16}$} & ASTM E119 & 175 \\
\hline & BNA12 & & & Hydrocarbon & 150 \\
\hline & BNA13 & & & Design Fire I & $\mathrm{NF}$ \\
\hline & BNA14 & & & Design Fire II & $\mathrm{NF}$ \\
\hline & BHA11 & \multirow{12}{*}{ HSC } & \multirow{4}{*}{$10^{-18}$} & ASTM E119 & 145 \\
\hline & BHA12 & & & Hydrocarbon & 110 \\
\hline & BHA13 & & & Design Fire I & 175 \\
\hline & BHA14 & & & Design Fire II & $\mathrm{NF}$ \\
\hline & BHA21 & & \multirow{4}{*}{$10^{-19}$} & ASTM E119 & 135 \\
\hline & BHA22 & & & Hydrocarbon & 105 \\
\hline & BHA23 & & & Design Fire I & 95 \\
\hline & BHA24 & & & Design Fire II & $\mathrm{NF}$ \\
\hline & BHA31 & & \multirow{4}{*}{$10^{-20}$} & ASTM E119 & 135 \\
\hline & BHA32 & & & Hydrocarbon & 105 \\
\hline & BHA33 & & & Design Fire I & 95 \\
\hline & BHA34 & & & Design Fire II & $\mathrm{NF}$ \\
\hline
\end{tabular}

*No failure

NSC beams and HSC beams is found to be small (within 5\%) and thus the same loading level is assumed for all the analyzed beams. For HSC beams, the spalling depth (thickness of concrete layer that spall off from the concrete section) is assumed not to exceed the clear concrete cover thickness for the analyzed beams.

\subsection{Material properties}

\subsubsection{Thermal and mechanical properties}

The temperature dependent properties that are important for establishing the fire response of RC structures include: thermal, mechanical and material specific properties such as permeability of concrete. For the fire resistance analysis of RC beams, the thermal and mechanical properties of NSC and reinforcing steel specified in the ASCE Manual ${ }^{25}$ are used. However, since the material properties in the ASCE manual are only applicable for NSC, the material properties derived by Kodur et al. ${ }^{26}$ are used for HSC.

In the cooling phase, the thermal properties of the constituent material (both concrete and steel) are assumed to be similar to that in the heating phase. For mechanical properties, linear interpolation between high temperature strength and residual strength is used to estimate the strength of both concrete and reinforcing steel in the cooling phase. The residual strengths for any concrete element or steel rebar are determined based on the maximum temperature attained in that element (or rebar). For concrete, the residual strength is assumed to be $75 \%$ of the high temperature strength determined at the maximum temperature attained in concrete. However, the residual strength of reinforcing steel is assumed based on the residual strength test conducted by Neves et al. ${ }^{27}$ on reinforcing steel. The variation of the residual strength of steel used in the analysis as a function of maximum temperature, as well as those reported from the residual strength test are shown in Fig. 7.

\subsubsection{Spalling related properties}

For spalling calculations, the following material properties are assumed:

- Isotherms : isotherms are used to predict the mass of liquid water inside concrete as a function of pore pressure and temperature. The isotherms, used in the analysis, are assumed to follow the semi empirical isotherms developed by Bazant et al. $^{28-30}$ The isotherms for the high strength concrete used in the analysis are shown in Fig. 8. It can be seen that the mass is 


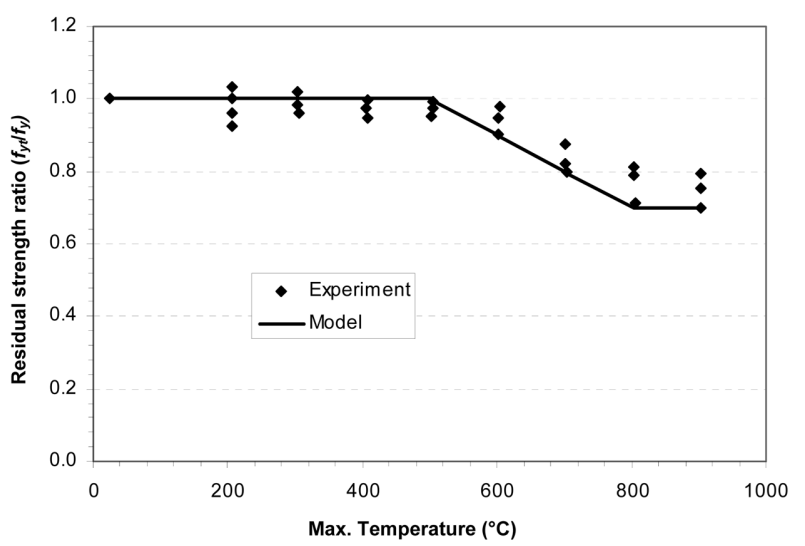

Fig. 7 Variation of residual strength of reinforcing steel as a function of temperature.

significantly reduced by increasing the temperature or reducing the pore pressure in concrete.

- Permeability: the variation of the permeability of concrete is assumed to follow the expression developed by Gawin et al. ${ }^{31}$ According to Gawin's model the intrinsic permeability of concrete at any temperature is give as:

$k_{T}=\left[10^{C_{T}\left(T-T_{0}\right)}\left(\frac{P_{V}}{P_{0}}\right)^{0.368}\right] k$

where, $k_{T}=$ intrinsic permeability of concrete at temperature $T, k=$ initial intrinsic permeability of concrete at room temperature, $P_{0}=101325 \mathrm{~Pa}, P_{V}=$ pore pressure $(\mathrm{Pa}), T_{0}=$ initial temperature $\left({ }^{\circ} \mathrm{C}\right)$, and $C_{T}=$ factor to account for the increase in concrete permeability at elevated temperatures. The factor $C_{T}$ in Eq. (3) is conservatively assumed to be 0.0025 . $^{11}$ Figure 9 shows the variation of concrete permeability as a function of temperature for different values of vapor pressure and for initial concrete permeability of $10^{-18} \mathrm{~m}^{2}$

- Tensile strength: the temperature dependent tensile strength of concrete is assumed as per Eurocode $2^{12}$ but with some modifications to avoid the conditions where the tensile strength becomes zero at relatively low temperatures $\left(600^{\circ} \mathrm{C}\right)$. The model follows the Eurocode constitutive relationships for tensile strength of concrete up to $550^{\circ} \mathrm{C}$. However, the Eurocode relationship is slightly modified for temperature range beyond $600^{\circ} \mathrm{C}$. In this range, the tensile strength of concrete is assumed to decrease gradually until it reduces to zero at $1,200^{\circ} \mathrm{C}$. This

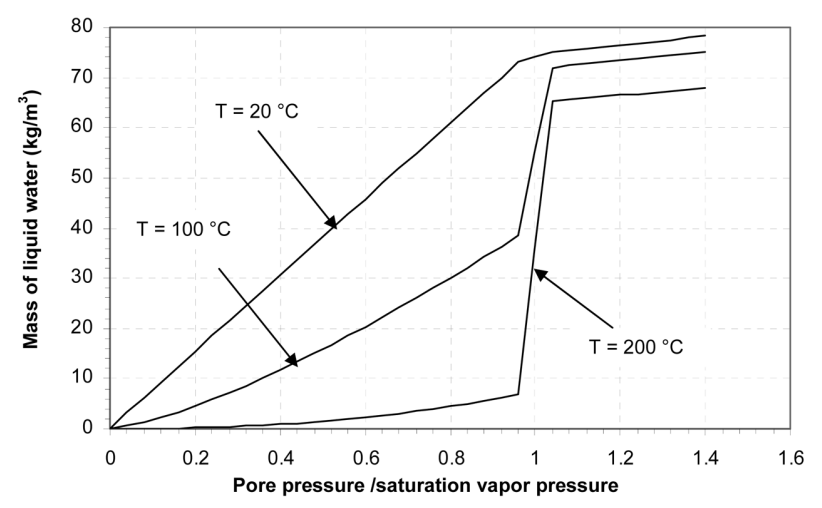

Fig. 8 Isotherms for HSC used in the analysis.

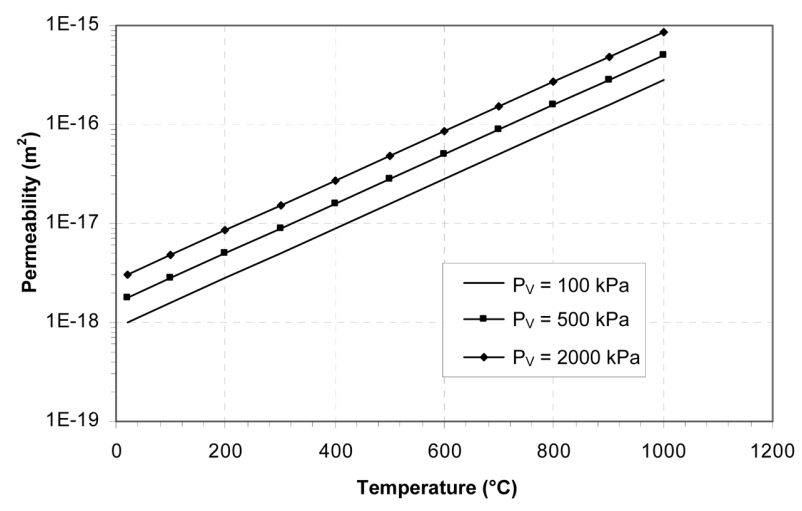

Fig. 9 Variation of permeability as a function of temperature and pore pressure.

modification is an insignificant one and is mostly to facilitate the numerical analysis (avoid convergence problems). It should be noted that tensile strength of concrete at $550^{\circ} \mathrm{C}$ is only $10 \%$ of the room temperature tensile strength.

\subsection{Fire exposure}

To investigate the effect of fire scenario on concrete spalling and fire resistance, all the beams were analyzed under two standard fire scenarios, namely ASTM E119 ${ }^{19}$ standard fire, and ASTM E1529 ${ }^{21}$ hydrocarbon standard fire, and under two design fire scenarios; namely Fire I and Fire II, taken from Eurocode 1. ${ }^{32}$ There is no decay phase in the time temperature curves of standard fires. However, in realistic (design) fires, there always exist a decay phase, since the amount of fuel or ventilation runs out leading to burn out in the compartment.

The parametric fire time temperature curve proposed in Eurocode $1,{ }^{32}$ together with the recent modifications suggested by Feasey and Buchanan, ${ }^{33}$ are selected to represent the design fires, Fire I and Fire II. According to Eurocode 1, the design fire consists of a growth phase and a decay phase. Feasey and Buchanan ${ }^{33}$ showed that both the growth and decay phases of the fire are influenced by compartment properties such as the fuel load, ventilation opening and wall linings. The time temperature curves for the two standard fire scenarios and the two design fire scenarios are shown in Fig. 10.

\section{Results and discussion}

Results from the case studies are presented in Table 1 and Figs. 11 to 16. The fire resistance of each beam is derived based on strength limit state consideration and is tabulated in Table 1. The effect of each of the parameters on spalling and fire resistance is

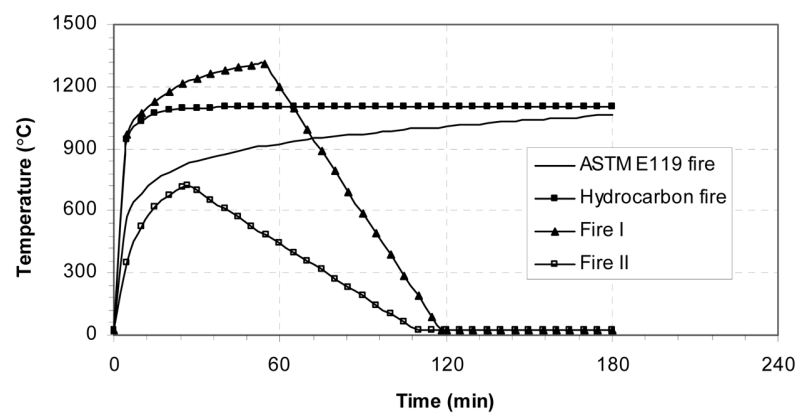

Fig. 10 Fire scenarios used in the case studies. 


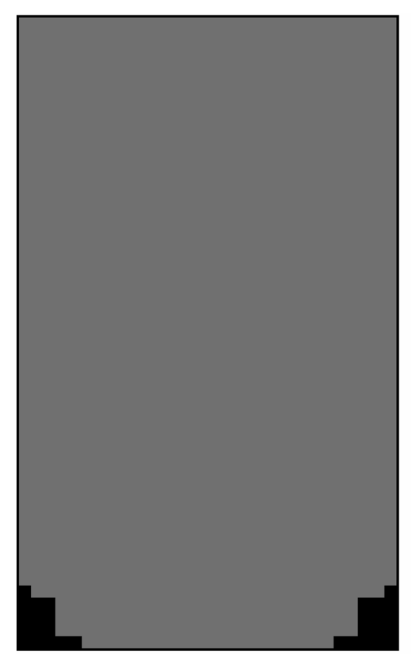

(a) Concrete spalling after 20 minutes of fire exposure

(b) Concrete spalling after 40 minutes of fire exposure

Fig. 11 Spalling in an HSC beam cross section exposed to ASTM E119 standard fire (Permeability $=10^{-18} \mathrm{~m}^{2}$ ).

discussed bellow.

\subsection{Effect of spalling}

A review of results from the analysis show that no spalling occurred in NSC beams (BNS11 to BNS14 and BNA11 to BNA14), whereas significant spalling occurred in HSC beams (BHS11 to BHS34 and BHA11 to BHA34). This is mainly attributed to the low permeability in HSC beams. The reduced permeability prevents the water vapor, generated with increasing temperatures in concrete, from escaping and this leads to build-up of vapor pressure in concrete. When this vapor pressure exceeds the temperature dependent tensile strength of concrete, layers of concrete spall away from concrete. However, in the case of NSC beams, the high level of permeability provides a mechanism for the water vapor to escape from the concrete and thus alleviates significant vapor pressure build up. Therefore, the developed vapor pressure in NSC remains bellow the critical tensile strength values and it does not cause concrete spalling. Figure 11 illustrates the spalled area in an HSC beam, with a permeability of $10,,^{-18}$ after 20 minutes and 40 minutes of fire exposure. It can be seen that the extent of spalling (ratio of area of spalled concrete to the original area of the concrete cross section) in the concrete section increases with fire exposure time. This can be attributed to the fact that once first spalling occurs, the pore pressure will build up subsequently in the inner layers of concrete leading to further spalling in the beam. The figure also shows more severe spalling at the bottom corners of the beam cross section. This can be attributed to higher temperatures experienced at the bottom corners due to exposure from two sides (bottom and side), which in turn leads to higher vapor pressure.

Figure 12 shows the effect of degree of permeability on the extent of spalling in HSC beams exposed to ASTM E119 standard fire. It can be seen that no spalling occurs in the first 8 minutes of fire exposure for the three values of permeability, namely; $10^{-18} \mathrm{~m}^{2}$ $10^{-19} \mathrm{~m}$, and $10^{-20} \mathrm{~m}^{2}$. This time delay is required for the development of significant level of pore pressure that is sufficiently large enough to cause spalling in concrete. This time lag generally increases with increased permeability of concrete due to the quick

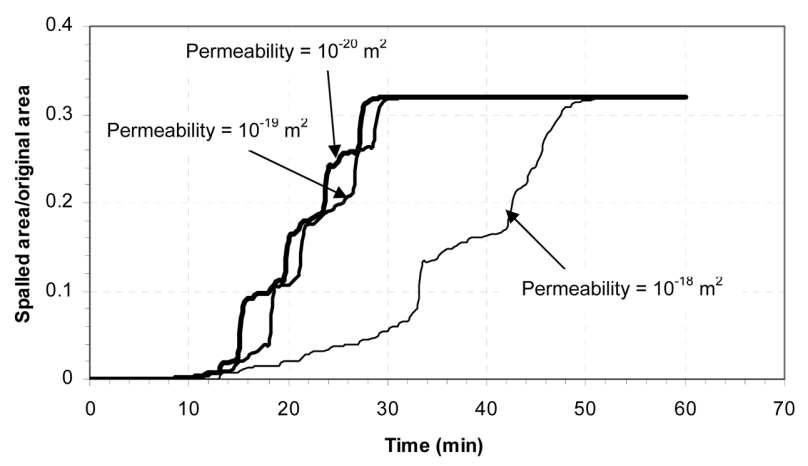

Fig. 12 Effect of permeability on spalling in HSC beams exposed to ASTM E119 fire.

development of pore pressure with low values of permeability. Figure 12 also shows that the extent of spalling increases with fire exposure time until it reaches constant value of about 0.32 and then maintains constant. The increase in the extent of spalling can be attributed to the continuous build up of pore pressure and spalling throughout fire exposure time. The rate of increase in the degree of spalling is higher for lower values of concrete permeability due to the quick development of pore pressure in the RC beams. The constant value (about 0.32 ) of the extent of spalling shown in Fig. 12 can be attributed to the assumption that spalling depth does not exceed the concrete cover, which is in agreement with what has been observed in fire tests. ${ }^{26}$

To illustrate the effect of spalling on fire response of $\mathrm{RC}$ beams, mid-span deflection are plotted as a function of fire exposure time for NSC and HSC beams in Figs. 13 16. Figures 13 and 14 illustrate the simply supported and restrained cases of NSC beam, while Figs. 15 and 16 illustrate the simply supported and restrained cases of HSC beams. The extent of fire induced spalling has significant effect on the deflection of the RC beams as can be seen by comparing Figs. 15 and 16 with Figs. 13 and 14. It can be seen that the deflection of HSC beams is much larger than that of NSC beams at any fire exposure time. This is primarily due to higher spalling observed in HSC beams, which in turn reduces the stiffness of the beam.

Spalling has detrimental effect on the fire resistance of RC beams as can be seen from Table 1 . As an illustration, the fire resistance of beam BNS11 (made of NSC with permeability of $10^{-16}$ ) is 145 minutes, whereas the fire resistance of beam BHS11 (made of HSC with permeability of $10^{-18} \mathrm{~m}^{2}$ ) is only 60 minutes. The large reduction in the fire resistance for HSC beams is due to the occur-

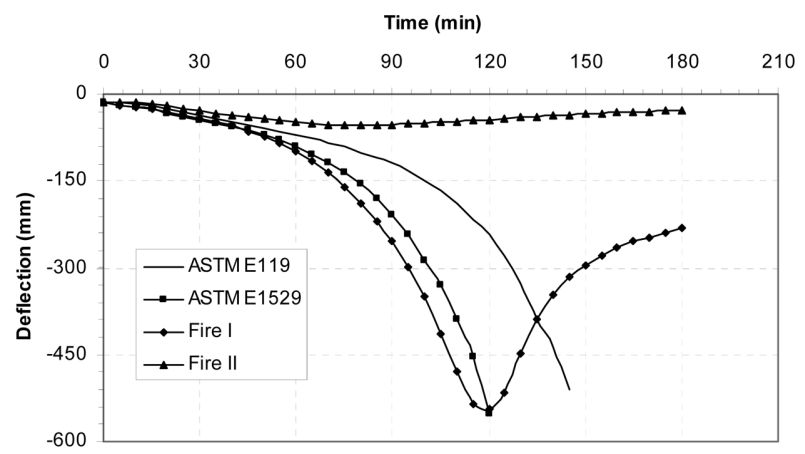

Fig. 13 Variation of deflection with fire exposure time for simply supported NSC beam. 


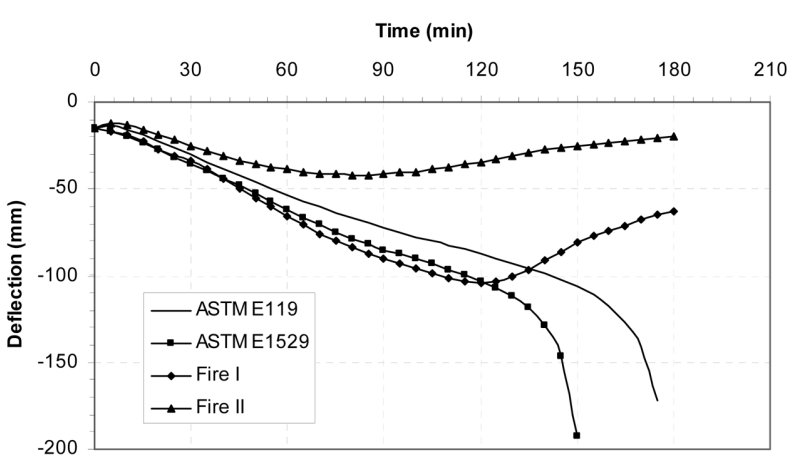

Fig. 14 Variation of deflection with fire exposure time for axially restraint NSC beam.

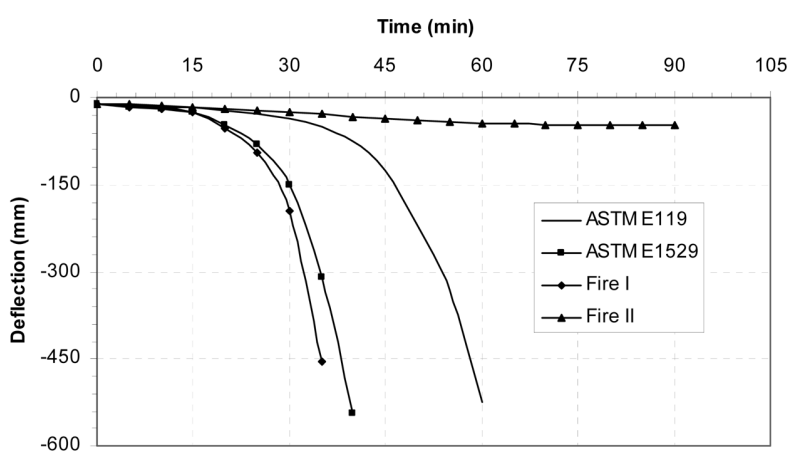

Fig. 15 Variation of deflection with fire exposure time for simply supported HSC beam (Permeability $=10^{-18} \mathrm{~m}^{2}$ ).

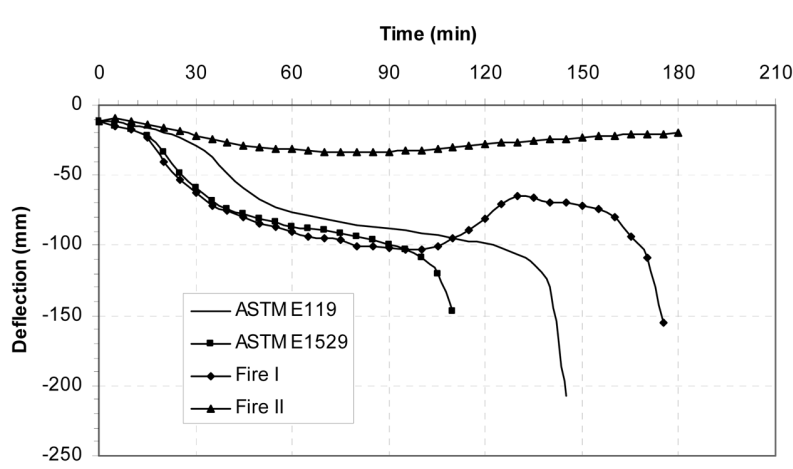

Fig. 16 Variation of deflection with fire exposure time for axially restrained HSC beam (Permeability $=10^{-18} \mathrm{~m}^{2}$ ).

rence of severe spalling in HSC beams. Spalling reduces the concrete cover thickness and thus accelerates the heat penetration to the steel reinforcement. Spalling also reduces the cross sectional area of the concrete beam. Thus, spalling significantly reduces the beam strength and stiffness which in turn leads to early failure and lower fire resistance in beams. Table 1 also shows that permeability of concrete has significant effect on the fire resistance for relatively high values of permeability. However, this effect is marginal for low concrete permeability as can be seen from Table 1 . This is because reduction in the permeability increases the degree of spalling at early stages of fire exposure time. However, the extent of spalling at later stages of fire exposure is maintained constant as can be seen from Fig. 12.

\subsection{Effect of fire scenario}

The analysis results show that the extent of spalling, in the HSC beams exposed to ASTM E1529 hydrocarbon fire and severe design fire (Fire I), is higher than that in the HSC beams exposed to ASTM E119 fire and moderate fire (Fire II). This can be attributed to the rapid increase in the temperature for the ASTM E1529 fire and Fire I at early stages of fire exposure as can be seen from Fig. 10. Results presented in Figs. 13-16 and Table 1 can be used to illustrate the effect of fire scenario on fire induced spalling and overall response of NSC and HSC beams.

It can be seen from the Figs. 13-16 that the deflection increases with time for all the beams at early stages of fire exposure. However, the figures show reduction (recovery) in the deflection for many of the beams exposed to the design fires at later stages of fire exposure. This is because of the decay phase in the design fires in which the beam starts cooling and recovers part of its strength and stiffness. Figure 15 shows no deflection recovery for beam BHS13 (simply supported), which is made of HSC and exposed to the sever design fire, Fire I. This is because of the occurrence of severe spalling in that HSC beam before it enters the cooling phase, which leads to early failure in the beam as can be seen from Fig. 15. However, Fig. 16 shows small recovery of deflection for HSC beam BHA13 (exposed to Fire I and axially restrained) followed by increase in deformation until the failure of the beam. The recovery in the deformation can be attributed to the fact that the beam recovers parts of its strength and stiffness. However, with further cooling, the concrete start to lose strength and stiffness (as the residual strength of concrete is less than the elevated temperature strength), and thus the overall stiffness of the beam starts to decrease again resulting in increased deflection of the beam as can be seen from Fig. 16.

Results from the analysis, presented in Table 1, show that the type of fire exposure has significant effect on the fire resistance of $\mathrm{RC}$ beams. Table 1 shows that the fire resistance for the beams exposed to the hydrocarbon fire is about 25 minutes lower than that for the beam under the ASTM E119 standard fire exposure. This is due to the rapid increase in fire temperature for the hydrocarbon fire as can be seen in Fig. 10. However, lower fire resistance values were obtained for all HSC beams (except beam BHA13), which are exposed to Fire I, than those obtained for beams exposed to other fire scenarios. This can be attributed to the rapid increase in temperature for Fire I which causes excessive spalling in the concrete beams and leads to early failure before the fire enters the cooling phase. However, for beam BHA13, the beam did not fail before the beam enters the cooling phase because that beam is axially restraint and has relatively high permeability. Thus, the beam starts to recover parts of its strength and stiffness. However, further cooling of the beam causes significant deterioration in the concrete and leads to large deformation and failure of the beam as can be seen in Fig. 16.

Table 1 shows that only six out of the sixteen cases of beams exposed to design fire (Fire I and Fire II) attain failure. It should be noted that all six cases were assumed to be exposed to Fire I (severe design fire). However, none of the beams exposed to Fire II (moderate design fire) attained failure. Hence, in spite of the severe conditions assumed for design fire (Fire I), failure is attained only in some of the beams, particularly those made of HSC. This result shows that in many applications, the fire resis- 
tance values computed based on standard fire scenarios, may be conservative if the resulting fires have a decay phase, similar to the ones used in this study.

\subsection{Effect of axial restraint}

The effect of axial restraint on the fire response of RC beams can be established by studying the results of the analysis on beams BNA11 to BHA34. A restrained RC beam, when exposed to fire, can develop significant axial force and this force varies with fire exposure time. The development of this additional restraining force alters the internal stresses in the beam (including higher tensile stresses), which might enhance the conditions for fire induced spalling. Thus, the axial restraint force is expected to influence the fire induced spalling in concrete. However, studying the effect of axial restraint on concrete spalling is very complex and is beyond the scope of this paper. Therefore, the coupled effect of axial restraint and spalling of concrete is not accounted for in the analysis. Nevertheless, spalling is considered in the analysis for both simply supported and axially restrained beams.

Results from the analysis show that axial restraint improves the fire response of RC beams even when excessive spalling is predicted. A comparison of trends in Figs. 13 and 15 with those in Figs. 14 and 16 indicates that axial restraint reduces the deflection of the beam at any fire exposure time. This is mainly due to the development of fire induced restraint forces, in axially restrained beams, and this creates an arch action leading to the development of a counter acting moment that neutralizes the load induced moments to some extent. ${ }^{13}$

It can be seen, from Table 1, that the axial restraint has significant effect on the fire resistance of RC beams. For all the analyzed $\mathrm{RC}$ beams, the fire resistance is higher for axially restrained beams than that for simply supported beams as shown in Table 1. As an illustration, the fire resistance of axially restrained beam BNA11 is 30 minutes higher than that of simply supported beam BNS11. This could be attributed to the arch action that is developed due to the axial restraint effect which improves the fire response of the $\mathrm{RC}$ beam.

\section{Practical implications}

Recent advances in concrete technology is leading to development of cost-effective and high performing concrete mixes for applications in built infrastructures. Fire induced spalling is one of the major concerns with newer types of concrete, such as HSC, when used in buildings. There is very limited guidance in current codes and standards for evaluating fire induced spalling in concrete. Further, the current techniques for mitigating spalling, such as addition of polypropylene fibers to concrete mix, are mainly derived based on observations in fire tests that are generally conducted on small scale specimens.

The lack of numerical models for evaluating spalling is hindering the wider use of newer types of concrete in building applications. Development of numerical models, such as the one presented here, will facilitate a cost-effective approach for evaluating fire induced spalling in RC members. By incorporating the material properties of fiber reinforced concrete, the proposed model can be used to develop cost-effective solutions, such as optimum amount of polypropylene fibers, for mitigating spalling.
The development of such guidelines, for incorporation into codes and standards, is in progress at Michigan State University.

\section{Conclusions}

Based on the results of this study, the following conclusions can be drawn:

- Spalling of concrete, which is directly related to concrete permeability, has detrimental effect on the fire resistance of RC beams. The fire resistance of HSC beams, with very low permeability, can be reduced by more than $50 \%$ due to fire induced spalling in concrete.

- Permeability has significant influence on fire induced spalling in concrete and thus on the fire resistance of $\mathrm{RC}$ beams. The effect of concrete permeability is more evident when moving from NSC to HSC.

- The type of fire exposure has significant influence on fire induced spalling and the fire resistance of RC beams. However, the extent of spalling can be higher under rapidly rising fire scenarios such as hydrocarbon fires. The conventional method of evaluating fire resistance, based on "standard" fire exposure, may be conservative even under severe design fire scenarios.

- The axial restraint has a significant effect on the fire resistance of RC beams. Even when spalling is likely to occur, the fire resistance of axially restrained beams is generally higher than that of simply supported beams.

\section{Acknowledgments}

The research, presented in this paper, is primarily supported by the Michigan State University Foundation, through Strategic Partnership Grant (Award No. SPG 71-4434), and the National Science Foundation CMMI program, Grant Number CMMI 0601178.

\section{References}

1. Phan, L. T., "Fire Performance of High-Strength Concrete," A Report of the State-of-the-Art. National Institute of Standards and Technology, Gaithersburg, MD, 1996, 105 pp.

2. Diederichs, U., Jumppanen, U. M., and Schneider, U., "High Temperature Properties and Spalling Behaviour of HSC," Proceedings of 4th Weimar Workshop on HPC, HAB Weimar, Germany, 1995, pp. 219 235.

3. Kodur, V. R. and Sultan, M. A., "Structural Behaviour of High Strength Concrete Columns Exposed to Fire," Proceedings: International Symposium on High Performance and Reactive Powder Concrete, Sherbrooke, Quebec, Vol. 4, 1998, pp. 217 232.

4. Danielsen, Ulf., "Marine Concrete Structures Exposed to Hydrocarbon Fires," Report, SINTEF - The Norwegian Fire Research Institute, 1997, pp. 56 76.

5. Bilodeau, A., Kodur, V. R., and Hoff, G. C., "Optimization of the Type and Amount of Polypropylene Fibres for Preventing the Spalling of Lightweight Concrete Subjected to Hydrocarbon Fire," Cement and Concrete Composites Journal, Vol. 26, No. 2, 2004, pp. $163 \sim 175$.

6. Hertz, K. D., "Limits of Spalling of Fire-Exposed Concrete," Fire Safety Journal, Vol. 38, 2003, pp. 103 116. 
7. Kodur, V. K. R., "Spalling in High Strength Concrete Exposed to Fire-Concerns, Causes, Critical Parameters and Cures," ASCE Structures Congress Proceedings, Philadelphia, U.S.A., 2000, pp. 1 8.

8. Fire Prevention, "Channel Tunnel Fire Protection Measures Questioned after Fire on HGV Wagon, Fire Prevention, 296, 1997.

9. Kodur, V. R., "Guidelines for Fire Resistance Design of High Strength Concrete Columns," Journal of Fire Protection Engineering, Vol. 15, No. 2, 2005, pp. 93 106.

10. Kodur, V. K. R. and Phan, L., "Critical Factors Governing the Fire Performance of High Strength Concrete Systems," Fire Safety Journal, Vol. 42, 2007, pp. 482 488.

11. Dwaikat, M. B. and Kodur, V. K., "Hydrothermal Model for Predicting Fire Induced Spalling in Concrete Structural Systems", Fire Safety Journal, in Press, 2008.

12. Eurocode 2, "prEN1992-1-2: Design of Concrete Structures," Part 1-2: General Rules - Structural Fire Design, Comité Europeén de Normalisation (CEN), Brussels, 2004.

13. ACI Committee 216.1, "Standard Method for Determining Fire Resistance of Concrete and Masonry Construction Assemblies," American Concrete Institute, Detroit; 2007.

14. Dwaikat, M. B. and Kodur, V. K. R., "A Numerical Approach for Modeling the Fire Induced Restraint Effects in Reinforced Concrete Beams," Fire Safety Journal, Vol. 43, No. 4, 2008, pp. 291 307.

15. Harmathy, T. Z., “A comprehensive Creep Model,” Journal of Basic Engineering, Vol. 89, No. 2,1967, pp. 496 502.

16. Harmathy, T. Z., "Fire Safety Design and Concrete," Concrete Design and Construction Series, Longman Scientific and Technical, UK, 1993.

17. Anderberg, Y. and Thelandersson, S., "Stress and Deformation Characteristics of Concrete at High Temperatures, 2. Experimental Investigation and Material Behaviour Model," Lund Institute of Technology, Sweden, 1976.

18. Kalifa, P., Chene, G., and Galle, C., "High-Temperature Behavior of HPC with Polypropylene Fibers: From Spalling to Microstructure," Cement and Concrete Research, Vol. 31, 2001, pp. 1487 1499.

19. ASTM Test Method E119-08a, "Standard Methods of Fire Test of Building Construction and Materials," American Society for Testing and Materials, West Conshohocken, PA, 2008.

20. Baroghel-Bouny, V., Mainguy, M., Lassabatere, T., and Coussy, O., "Chatacterization and Identification of Equilibrium and Transfer Moisture Properties for Ordinary and High-Performance Cementations Materials," Cement Concrete Research, Vol. 29, 1999, pp. 1225 1238.
21. ASTM Test Method E1529, "Standard Test Methods for Determining Effects of Large Hydrocarbon Pool Fires on Structural Members and Assemblies," American Society for Testing and Materials, West Conshohocken, PA, 1993.

22. Kodur, V. R. and Dwaikat, M. B., "Performance-Based Fire Safety Design of Reinforced Concrete Beams," Journal of Fire Protection Engineering, Vol. 17, No. 4, 2007, pp. 293 320.

23. ACI 318-2008, "Building Code Requirements for Reinforced Concrete," ACI 318-02 and Commentary, American Concrete Institute, Detroit, MI, 2008.

24. ASCE 7-05, "Minimum Design Loads for Buildings and Other Structures," American Society of Civil Engineers, Reston, VA, 2005.

25. Lie, T. T. (Editor), "Structural Fire Protection," $A S C E$ Manuals and Reports of Engineering Practice, No 78, American Society of Civil Engineers, New York, 1992.

26. Kodur, V. K. R., Wang, T., and Cheng, F., "Predicting the Fire Resistance Behavior of High Strength Concrete Columns," Cement \& Concrete Composites, Elsevier Ltd., Vol. 26, No. 2, 2004, pp. 141 153.

27. Neves, I. C., Rodrigues, J. C., and Loureiro, A. P., "Mechanical Properties of Reinforcing and Prestressing Steels after Heating," Journal of Materials in Civil Engineering, Vol. 8, No. 4, 1996, pp. $189 \sim 194$.

28. Bazant, Z. P., and Thonguthai, W., "Pore pressure and Drying of Concrete at High Temperature," Journal of the Engineering Mechanics Division, ASCE, Vol. 104, No. EM5, 1978, pp. 1059 1079.

29. Bazant, Z.P. and Thonguthai, W., "Pore Pressure in Heated Concrete Walls: Theoretical Prediction," Magazine of Concrete Research, Vol. 31, No. 107, 1979, pp. 67 76.

30. Bazant, Z. P., Chern, J. C., and Thonguthai, W., "Finite Element Program for Mositure and Heat Transfer in Heated Concrete," Nuclear Engineering and Design, Vol. 68, 1981, pp. $61 \sim 70$.

31. Gawin, D., Majorana, C. E., and Schrefler, B. A., "Numerical Analysis of Hygro-thermic Behaviour and Damage of Concrete at High Temperature," Magazine of Cohesive Frictional Material, Vol. 4, 1999, pp. 37 74.

32. Eurocode 1, "ENV 1991-2-2: Basis of Design and Design Actions on Structures," Part 2-2: Actions on Structures Exposed to Fire, European Committee for Standardization, 1994.

33. Feasey, R. and Buchanan, A. H., "Post Flash-over Fires for Structural Design," Fire Safety Journal, Vol 37, No 1, 2002, pp. $83 \sim 105$. 